\title{
A questão racial em sala de aula
}

The racial question in classroom

\author{
La question raciale en salle de classe
}

\author{
Gisele Gasparelo VOLTANI
}

Silvia Helena MARTINS

\section{RESUMO}

Este depoimento é resultado de um projeto sobre o tema das relações raciais em sala de aula através da literatura infantil em língua portuguesa.

Palavras-chave: Questão racial, Escola, Literaturạ.

\section{ABSTRACT}

This report is result of a project about the question of racial relations in classroom using child's literature in Portuguese Language.

Index Terms: Racial question, School, Literature.

\section{RÉSUMÉ}

Ce témoignage est le résultat d'un projet sur le thème des relations raciales en salle de classe en utilisant la littérature pour enfant en langue portuguaise.

Mots-clés: Question raciale, École, Littérature 


\section{Questão Racial em sala de aula}

A sociedade brasileira criou e dá crédito ao grande mito da igualdade racial no nosso país. Para si e para muitos outros países, o caso do Brasil parece ser exemplar em termos de convivência e eqüidade étnico-cultural. Todavia, o racismo existe. Muito pior: um racismo cordial que teima em parecer inexistente. A escola, sendo uma das instituições formadoras da identidade, é ao mesmo tempo influenciada pelos valores correntes da sociedade em que está inserida e reprodutora de padrões nela vigentes e reiterados. Sendo assim, o sistema de educação brasileiro, fundado no mito da igualdade da lei para todos, esconde também uma realidade cruel: a discriminação racial.

Segundo Fernandes (2005), uma das tendências do mundo contemporâneo é o multiculturalismo, que deve se traduzir no respeito e valorização das diferenças socioculturais. Para cumprir sua tarefa humanista, a escola precisa mostrar aos alunos que existem outras culturas, dialogando então com todas as culturas e concepções de mundo.

É neste contexto que a implementação da Lei 10.639/03, Diretrizes curriculares nacionais para a educação das relações étnico-racionais, indica um caminho para que a instituição escolar repare os resultados da discriminação de longa data. Pensamos acerca destas questões e levamos em consideração o público a que se destinava nosso projeto: alunos de uma $2^{\mathrm{a}}$ série de uma escola pública de periferia, cuja maioria dos alunos é negra, e elaboramos um projeto para abordar o tema das diferenças raciais. Utilizamos quatro aulas de uma hora para a realização da atividade de transposição didática e, tendo em vista a maturidade da faixa etária dos alunos, optamos pela utilização de livros de literatura infantil, além de debates e atividades. 
Em nossa primeira aula lemos com a sala o livro Os dez amigos (2001). Este livro infantil trata de maneira divertida a diferença dos dedos das mãos e a importância de todos eles. Enquanto uma de nós lia a história, a outra fazia das mãos os personagens, um recurso lúdico para melhor prender a atenção das crianças e conseguir uma maior compreensão. Finda a narrativa, levantamos com as crianças a importância das diferenças entre os aparentes iguais, ressaltando o aspecto da variação e apontando o equívoco de se associar às diferenças uma questão de superioridade. Ao final, cada um desenhou num papel suas próprias mãos enfeitando da maneira como quisesse. Um cartaz foi exposto na escola com uma variedade imensa de "mãozinhas" e pudemos trabalhar novamente com base nisso a diferença e a igualdade - não havia uma única mão igual, mas todas eram mãos.

$\mathrm{Na}$ segunda aula, lemos outro livro Menina bonita, laço de fita (2004). Este livro infantil trata de maneira poética a diferença racial. Um coelho branco se apaixona por uma menina negra e a interpela sobre a origem da sua bela cor. Depois de experimentar sem sucesso todas as justificativas inventadas pela garota, sua mãe esclarece dizendo da hereditariedade das características da avó. As ilustrações foram reproduzidas em retroprojetor. A classe também participou da narrativa, repetindo a pergunta que o coelho branco sempre fazia; "Menina bonita do laço de fita, qual é o seu segredo para ser tão pretinha?" Em alguns alunos via-se a relutância na palavra "pretinha", sendo ela substituída espontaneamente por "bonitinha". Ao fim da narrativa, estimulamos os alunos a comentarem a história e a fazer relações com a história da aula anterior e depois com a sua própria, percebendo que, assim como a menina, eles também parecem com seus antepassados. E, independente da cor, todos eram bonitos como a menina bonita. Um dos alunos afirmou sem rodeios que ela não era bonita por ser preta. Este fato nos possibilitou um debate com a sala, questionando suas convicções pré-existentes sobre beleza, por 
exemplo. Isso já demonstrava quão difícil é mudar "verdades" tão fortemente arraigadas em crianças ainda tão pequenas.

Na terceira aula, ao invés de aula expositiva sobre a escravidão no Brasil, introduzimos nessa etapa mais um livro de história infantil, O Amigo do Rei (2005). Antes de a história ser contada, perguntamos como seria um alemão e as crianças chegaram rapidamente ao consenso: branco, louro, de olhos claros. Propomos a caracterização de um japonês e novamente um consenso: olhos puxados, cabelo preto e liso. Então perguntamos sobre um tipo físico brasileiro. Não houve consenso. Partimos daí para falar da composição étnica do Brasil pela sua história: o índio, o branco, o negro e, mais tarde, os imigrantes. Lemos a narrativa de Ruth Rocha, que se situa no tempo da escravidão negra do Brasil e conta a história da amizade entre um menino filho de fazendeiro e de um escravo de sua propriedade. As duas crianças acabam fugindo juntas por causa de um desentendimento com o pai e são recebidas num quilombo. Lá, o garoto negro é considerado rei, já que seu pai o era na África. O garoto branco, motivado pela saudade dos seus, acaba voltando para a casa, mas os dois crescem e ambos acabam lutando pela causa abolicionista. A atividade proposta era uma caça-palavra referente à história e a pintura de uma das ilustrações do livro, em que os meninos aparecem brincando juntos.

Tivemos resultados interessantes com essa última atividade. Alguns alunos pintaram os dois garotos como brancos, mas alguns também pintaram os dois como negros. Em um dos grupos, levantamos uma outra questão: uma das crianças nos chamou para confirmar se o lápis de cor bege que ela tinha nas mãos era a "cor de pele". Devolvemos com outra questão “A cor de pele de quem? Minha ou sua? Ou do seu colega?" Isso causou um debate entre eles e, por fim, chegamos à conclusão de que não havia uma só cor de pele e aquele lápis não poderia ser assim denominado. 
Na última aula, pretendíamos mostrar a importância do negro e de sua cultura na formação da sociedade brasileira através da presença de seus elementos no cotidiano da sala. Isso deveria ser feito através de recortes em revistas, seguido de montagem de cartazes. No entanto, a proposta de recortes tornou-se impossível, dado que não havia negros nas revistas. Isso foi discutido com os alunos e a proposta de atividade foi modificada. Os alunos cortaram das revistas fotos onde as pessoas estavam convivendo bem, independentes de sua cor. Montamos dois grandes cartazes intitulados "Convivendo com as diferenças".

\section{Conclusões Finais: relações raciais na escola}

O trabalho com os livros de literatura infantil se mostrou excelente, pois o recurso de contar histórias prendeu a atenção dos alunos e passou a mensagem pretendida pelo grupo de professores-estudantes de uma maneira lúdica. A temática foi desenvolvida de maneira satisfatória e a participação das crianças foi total.

Constatamos que ainda há uma certa resistência de algumas crianças em tratar da temática racial. Preconceitos que, devido à espontaneidade delas, não são nada velados. Sabemos o quanto a concepção de homem e a articulação das identidades social e individual tecem a identidade do sujeito, toda a ação humana é resultado da apropriação de valores simbólicos por parte do individuo de uma dada sociedade. Tais valores são, portanto, culturalmente compartilhados e reforçados através de múltiplas relações interpessoais.

A escola, que faz parte desta sociedade, também é carregada de valores simbólicos por ela produzidos e legitimados. Não é de estranhar esta dificuldade das crianças em tratarem sobre o tema das relações raciais já que este tema é tão difícil de ser tratado na sociedade brasileira como um todo. 
Nossa última aula provou como é difícil encontrar a equidade racial nos materiais impressos: simplesmente não havia fotos de negros nas revistas! E assim também ocorre na mídia televisiva e em outras instâncias sociais.

As Diretrizes curriculares nacionais para a educação das relações étnico-racionais foram aprovadas, o que já é uma vitória. Entretanto, é urgente a demanda por investimentos na área de formação docente que permitam aos professores estarem de acordo com estas Diretrizes e serem capazes de formar cidadãos cujo exercício de convivência étnico-cultural seja baseado no reconhecimento e no respeito. Além disso, é muito importante a existência de materiais didáticos adequados, além de possibilidades de troca de experiência entre escolas e entidades que trabalham nesta direção.

Acreditamos que este trabalho pôde contribuir para uma nova visão do tema da igualdade racial e trazer uma valorização de sua identidade social. Sabemos que estas crianças ainda terão muito a aprender e vivenciar para poder entender a dimensão histórica do preconceito racial. Sendo assim, acreditamos que nosso pequeno trabalho foi uma boa introdução ao tema.

\section{Referências Bibliográficas}

FERNANDES (2005). Ensino de história e diversidade cultural: desafios e possibilidades. Cad. Cedes, Campinas, v. 25, n. 67, p. 378-388, set./dez.

MACHADO, Ana Maria (2004). Menina bonita, laço de fita. São Paulo: Ática.

ROCHA, Ruth (2005). O amigo do rei. São Paulo: Ática.

ZIRALDO (2001). Os Dez Amigos. São Paulo: Melhoramentos. 


\section{Autoras}

\section{Gisele Gasparelo Voltani}

Bacharel e licenciada em História (FFLCH-USP) e aluna do $3^{\circ}$ ano de Pedagogia (FE-USP). Professora Titular de Ensino Fundamental I na rede pública municipal de São Paulo (desde 1999) e Professora Orientadora de Sala de Leitura (desde 2002).

Contato: gizbr@yahoo.com.br

\section{Silvia Helena Martins}

Aluna do $3^{\circ}$ ano de Pedagogia (FE-USP). Professora Estagiária do Projeto Ler e Escrever (desde 2008) A prática docente ocorreu numa escola municipal na periferia de São Paulo e envolveu alunos do $2^{\circ}$ ano do Ensino Fundamental - Ciclo I

Contato: skasika@hotmail.com

\section{Como citar este depoimento:}

MARTINS, Silvia Helena e VOLTANI Gisele Gasparelo. A questão racial em sala de aula. Revista ACOALFAplp: Acolhendo a Alfabetização nos Países de Língua portuguesa, São Paulo, ano 3, n. 6, 2009. Disponível em: $<$ http://www.acoalfaplp.net>. Publicado em: março 2009.

Recebido em junho de 2008/ Aprovado em julho de 2008 